\title{
Boiling Closure Model Validation/Development Effort with TAMU Experimental Data
}

Junsoo Yoo

August 2016

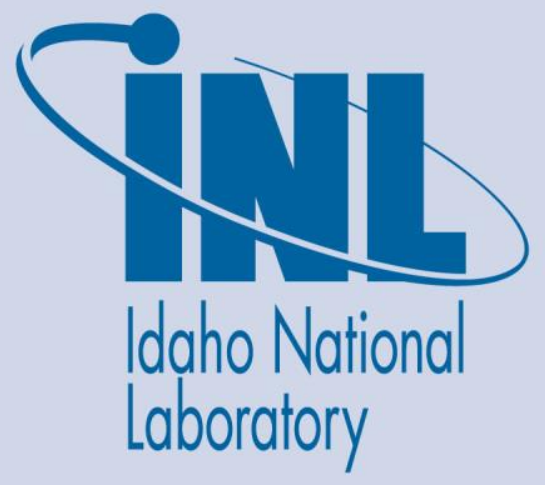

The INL is a U.S. Department of Energy National Laboratory operated by Battelle Energy Alliance 


\section{DISCLAIMER}

This information was prepared as an account of work sponsored by an agency of the U.S. Government. Neither the U.S. Government nor any agency thereof, nor any of their employees, makes any warranty, expressed or implied, or assumes any legal liability or responsibility for the accuracy, completeness, or usefulness, of any information, apparatus, product, or process disclosed, or represents that its use would not infringe privately owned rights. References herein to any specific commercial product, process, or service by trade name, trade mark, manufacturer, or otherwise, does not necessarily constitute or imply its endorsement, recommendation, or favoring by the U.S. Government or any agency thereof. The views and opinions of authors expressed herein do not necessarily state or reflect those of the U.S. Government or any agency thereof. 


\title{
Boiling Closure Model Validation/Development Effort with TAMU Experimental Data
}

\author{
Junsoo Yoo
}

August

Idaho National Laboratory Idaho Falls, Idaho 83415

http://www.inl.gov

Prepared for the

U.S. Department of Energy

Office of Nuclear Energy

Under DOE Idaho Operations Office

Contract DE-AC05-00OR22725 


\begin{abstract}
This report describes a model validation and developmental effort in INL based on the analysis of experimental data taken from TAMU subcooled flow boiling facility. This report first describes briefly the test loop, experimental strategy, measurement techniques, data quality achieved, and test boundary conditions. Then, two main topics are discussed based on the experimental observation, bubble departure frequency and sliding bubble characteristics.

The comparison of experimental data with the prediction of bubble departure frequency models shows that the predictive capability of existing models depends strongly on flow conditions. Also, the best performance region of each bubble departure frequency model could be determined from this analysis.

Another critical achievement through this study is that the limitation of existing CFD boiling models dealing with sliding bubble effect was clearly identified. Specifically, the experimental observation indicates that the wall area influenced by sliding bubbles is not just a function of bubble size, but also depends strongly on sliding bubble trajectory and sliding distance. As a result, the bubble influence factor $(K)$ for the small size of sliding bubbles was often found substantially higher than those reported in literature. In this regard, an effort is currently being made in INL to develop a new model to predict the sliding bubble effect on wall heat transfer based on the insight achieved from TAMU subcooled flow boiling experiment.
\end{abstract}




\section{CONTENTS}

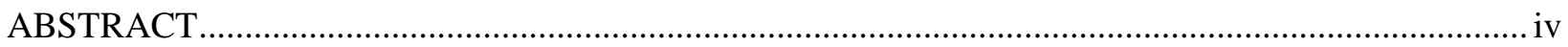

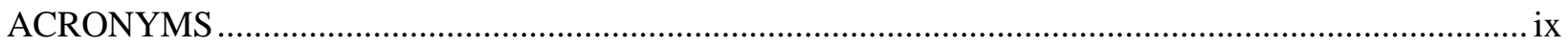

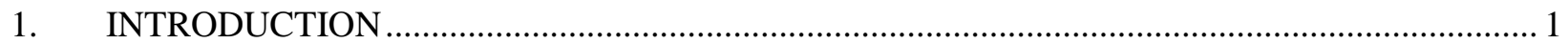

2. TAMU'S FACILITY FOR SUBCOOLED FLOW BOILING EXPERIMENT AND

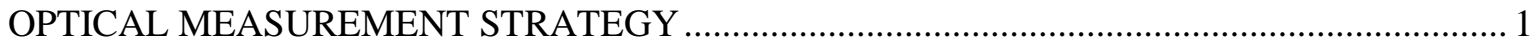

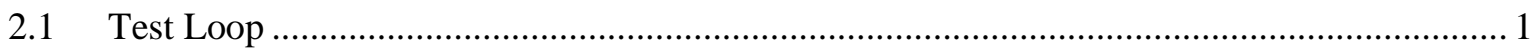

2.2 Experimental Strategy and Measurement Techniques ...................................................... 2

3. TEST BOUNDARY CONDITIONS AND COLLECTED DATA …........................................ 4

4. COMPARISON OF BUBBLE DEPARTURE FREQUENCY MODELS WITH THE

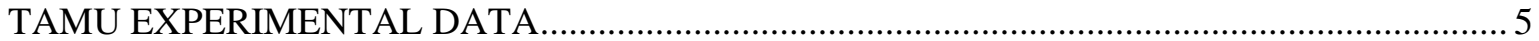

5. IDENTIFICATION OF LIMITATION IN CFD BOILING MODEL APPROACH

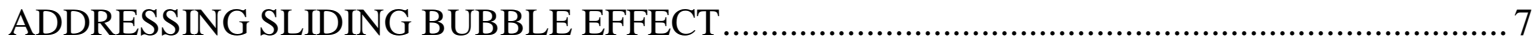

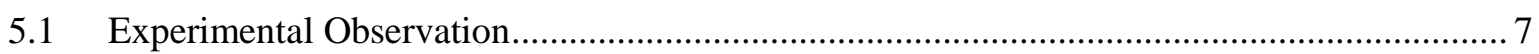

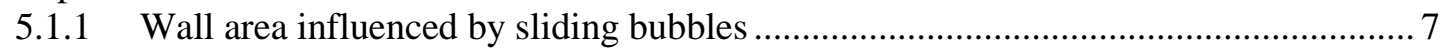

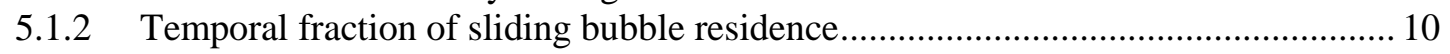

5.2 New/Improved Modeling Need and Ongoing Work in INL ............................................ 13

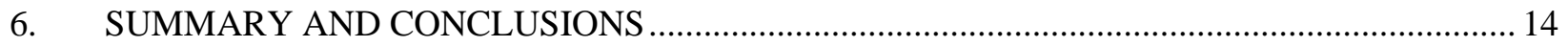

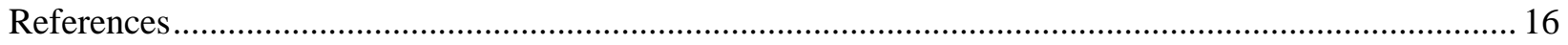

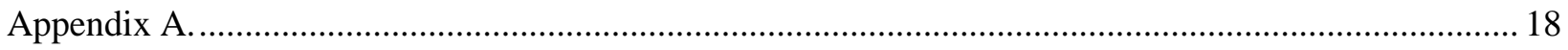




\section{FIGURES}

Figure 1. Cameras arrangement around transparent test section in TAMU subcooled flow boiling

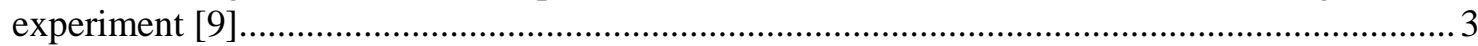

Figure 2. Established experimental techniques for high-fidelity optical measurement of boiling............... 3

Figure 3. Strategy for enhancing the observation of subcooled flow boiling characteristics [6]................ 4

Figure 4. Prediction capability of bubble departure frequency models depending on Re (left) and

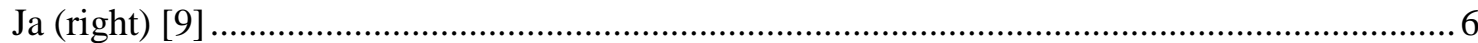

Figure 5. Best performance region of bubble departure frequency models depending on flow

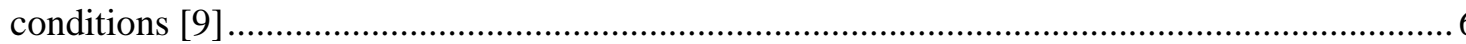

Figure 6. Variation of bubble release frequency by the changes in Ja at different mass fluxes $(\mathrm{G})$

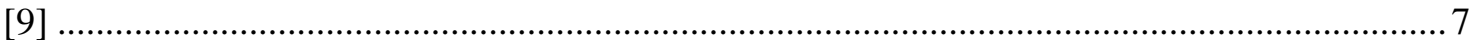

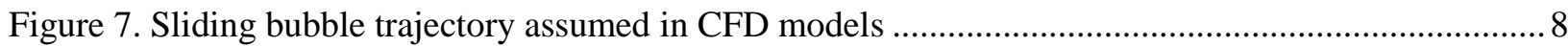

Figure 8. Measurement of sliding bubble spreading area $(S)$ and bubble influence area $(K)$................... 9

Figure 9. Bubble influence factor $(\mathrm{K})$ depending on the size of sliding bubble for a given sliding distance

Figure 10. A typical development of $\overline{F_{R}}(y, z)$ along the flow path $\left(\mathrm{H}_{0}\right.$ is heater width $(=7.5 \mathrm{~mm})$ and $\mathrm{H}$ is horizontal position within $\mathrm{H}_{0}$ )

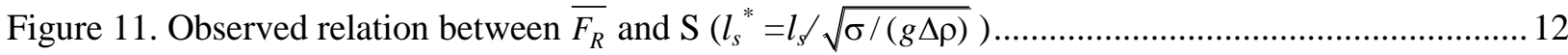

Figure 12. Degree of wall heat transfer enhancement $\left(\mathrm{H}_{\text {downstream }} / \mathrm{H}_{\text {upstream }}\right)$ through the sliding distance $l_{s}^{*}=11.8$ depending on $F_{R}$

Figure 13. New experimental finding (top) and modeling strategy (bottom) for bubble influence factor $(K)$ and bubble spreading factor $(S)$

\section{TABLES}

Table 1. Summary of test conditions in TAMU subcooled flow boiling experiment [9] 


\section{ACRONYMS}

HSC High Speed Camera

INL Idaho National Laboratory

IR Infrared

TAMU Texas A\&M University 


\section{Boiling Closure Model Validation/Development Effort with TAMU Experimental Data}

\section{INTRODUCTION}

A subcooled flow boiling experiment has recently been performed in Texas A\&M University (TAMU) with an unique experimental strategy (e.g., multi-scale measurement, single nucleation site approach) and by employing advanced optical measurement techniques. In this experiment a special attention has also been paid to the data analysis in order to characterize the 'typical' bubble or heat transfer behavior at each given test condition [1]. As a consequence, the experimental data taken from this facility ensures highfidelity as well as provides us with an opportunity to investigate a wide range of subcooled flow boiling parameters. Additionally, it is important to note that during this study the bubbles departing from a single nucleation site tended to slide along the heated wall, which has naturally driven our main interest to the sliding bubble characteristics and associated wall heat transfer.

The sliding bubbles' effect on wall heat transfer has consistently been reported in literature by many researchers [2-4]. Also, due to the importance of sliding bubbles in surface cooling aspect, efforts have been made to address the effect through modeling [5, 6]. However, the fundamental mechanism associated with sliding bubble effect on wall heat transfer is yet to be well understood and thus it is still among the topics of great interest within boiling heat transfer community.

In this report, a brief discussion is first made on the TAMU subcooled flow boiling experiment, the overall research scope, and the data characteristics/quality achieved (sections 2,3), the details of which are also available in Yoo et al. [1]. Then, the performance of the existing bubble departure frequency models to predict the data taken from the TAMU experiment is discussed in section 4. Lastly, the recent experimental findings revealing the specific knowledge gap between the existing CFD boiling models and the actual physics observed during this work is discussed in section 5. Particularly, the wall area influenced by sliding bubbles is of interest and the ongoing model developmental work in INL is described.

\section{TAMU'S FACILITY FOR SUBCOOLED FLOW BOILING EXPERIMENT AND OPTICAL MEASUREMENT STRATEGY}

\subsection{Test Loop}

Detailed information on TAMU subcooled flow boiling experiment is provided by Yoo et al. [1]. This section describes the experimental setup only briefly by focusing on its main features. The measurement of subcooled flow boiling was conducted for a vertical, square, upward flow channel. As a working fluid, the refrigerant Novec-7000 (3M Inc.) was used. The side walls of test section were made of acrylic (transparent to visible light) except for the heater wall on one side. The glass substrate was attached to the 
heater wall side on which an electrically conductive Indium-Tin-Oxide (ITO) film was deposited so that heat can be provided to the test channel through Joule heating. ITO was adopted as a heating element due to its special optical property (i.e., transparent to visible light and opaque to infrared radiation), allowing us to measure the heater surface (hereafter, wall) temperature using infrared (IR) camera without damaging the quality of high-speed bubble imaging through high-speed cameras. The flow area through the test section was $10 \times 10 \mathrm{~mm}^{2}$ while the heated surface area on the heater wall side was $7.5 \times 224 \mathrm{~mm}^{2}$. The experiment was performed with the range of mass flux $(\mathrm{G}) 140-700 \mathrm{~kg} / \mathrm{m}^{2} \mathrm{~s}$, inlet subcooling $\left(\Delta \mathrm{T}_{\text {sub,in }}\right)$ 4.5-13.5 ${ }^{\circ} \mathrm{C}$, and wall heat flux $\left(\mathrm{q}_{\mathrm{w}}\right) 8.1-35.1 \mathrm{~kW} / \mathrm{m}^{2}$.

One particular feature of this experiment is that only a single artificial nucleation site was activated at axial location $\mathrm{L} / \mathrm{L}_{0} \approx 0.41$ ( $\mathrm{L}_{0}$ is the total heated length and $\mathrm{L}$ is the axial location within $\mathrm{L}_{0}$ ) (see Figure 1). This was to enhance the observation of bubbles and associated wall heat transfer through the optical measurement techniques by controlling the complexity of flow boiling phenomena. More specifics on the strategy applied to TAMU subcooled flow boiling experiment are described in the following section.

\subsection{Experimental Strategy and Measurement Techniques}

The high-speed bubble imaging and infrared (IR) thermometry has been simultaneously applied to observe the bubble and wall heat transfer parameters at subcooled flow boiling conditions. The experimental method to achieve both accurate wall temperature measurement (using IR thermometry) and enhanced flow visualization have been established from the previous work by Yoo et al. [7], including extensive validations for IR measurement accuracy. Also, several measurement issues of high-speed bubble imaging is discussed in [8] in which an automatic image analysis algorithm is developed as well. Then, by incorporating all these efforts the truly high-fidelity data could be achieved from the TAMU subcooled flow boiling experiment. In Figure 2, the established techniques which serve to enhance the data quality obtained from TAUM subcooled flow boiling experiment is summarized.

Figure 3 shows a unique experimental strategy taken during the TAMU experiment to overcome the general difficulties of optical measurement under boiling conditions. Considering that the high phenomenological complexity and the optical distortion caused by boiling usually prevent us from observing the underlying physics, the number of nucleation site was limited to single (i.e., bottom-up approach). Also, the bubbles' behavior was captured with multiple scales (i.e., high- and low-resolutions) to investigate the various aspects of bubble characteristics (multi-scale observation). Moreover, a variety of parameters were observed together, allowing us to gain better insight into the relation among the measured parameters (multi-variable measurement). The effects of test boundary conditions (e.g., mass flux, subcooling degree, wall heat flux) on bubbles' characteristic and associated wall heat transfer were systematically observed. Lastly, efforts were made to analyze the numerous images to characterize the 'typical' bubble behavior and wall heat transfer at a given condition with high statistical significance. More details on the present experiment and the data quality achieved are presented in Yoo et al. [1]. 


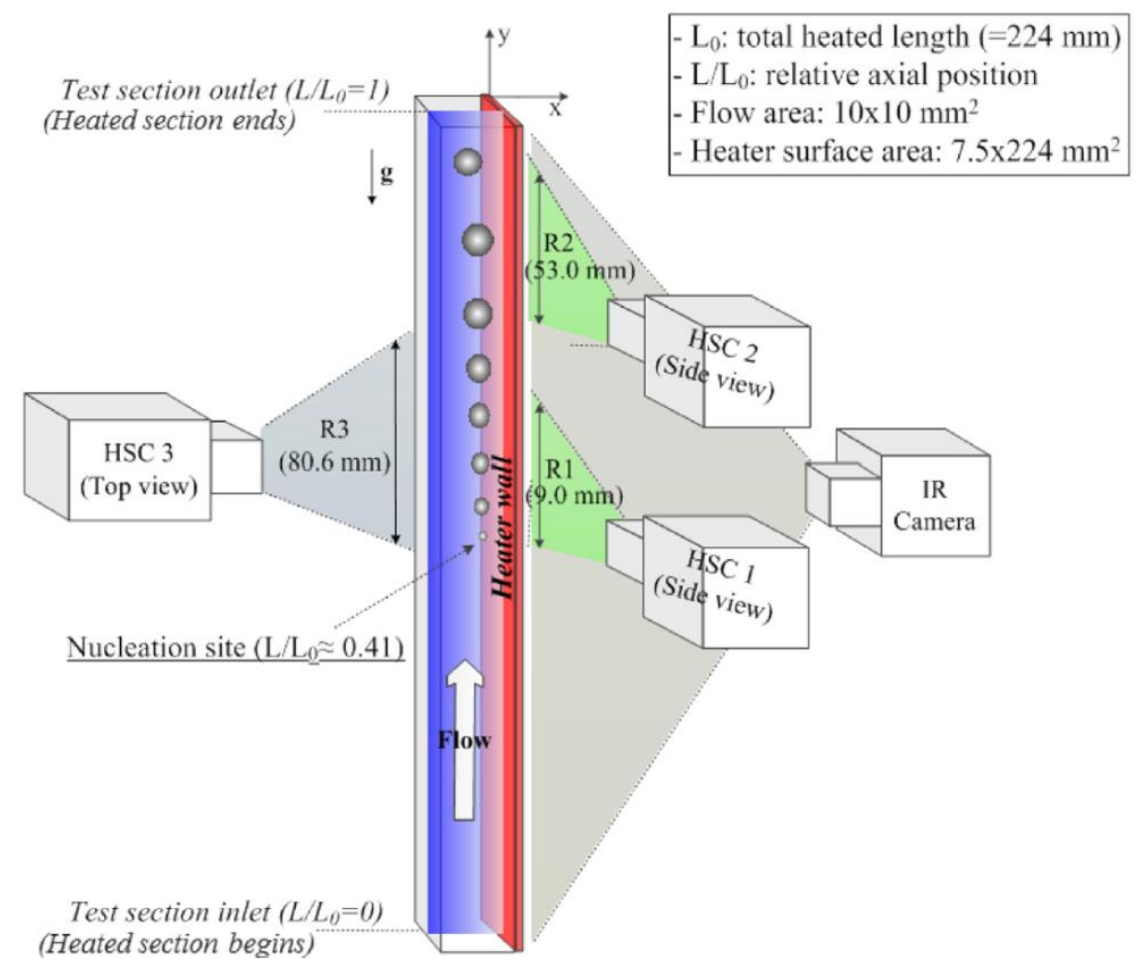

Figure 1. Cameras arrangement around transparent test section in TAMU subcooled flow boiling experiment [9]

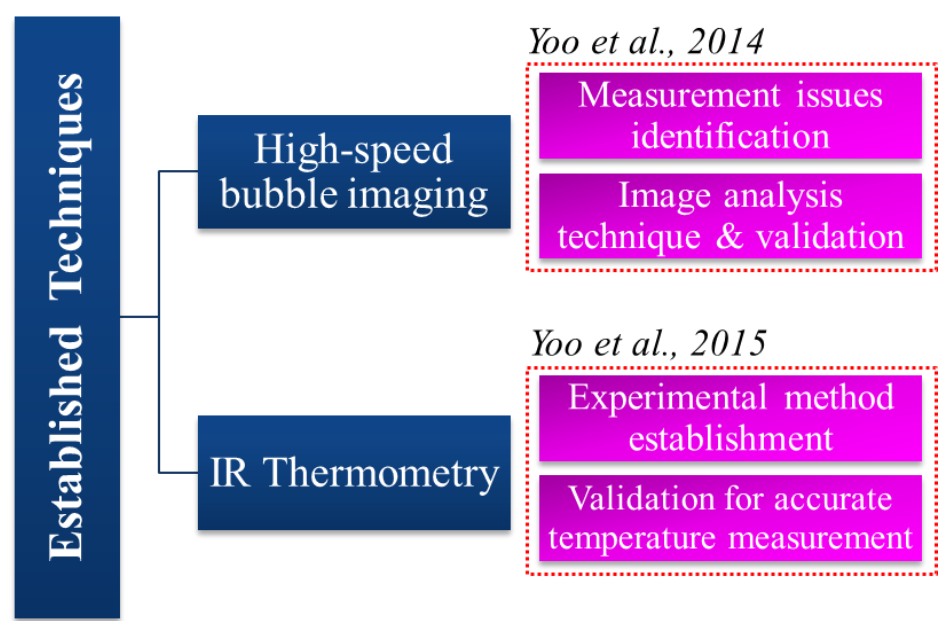

Figure 2. Established experimental techniques for high-fidelity optical measurement of boiling 


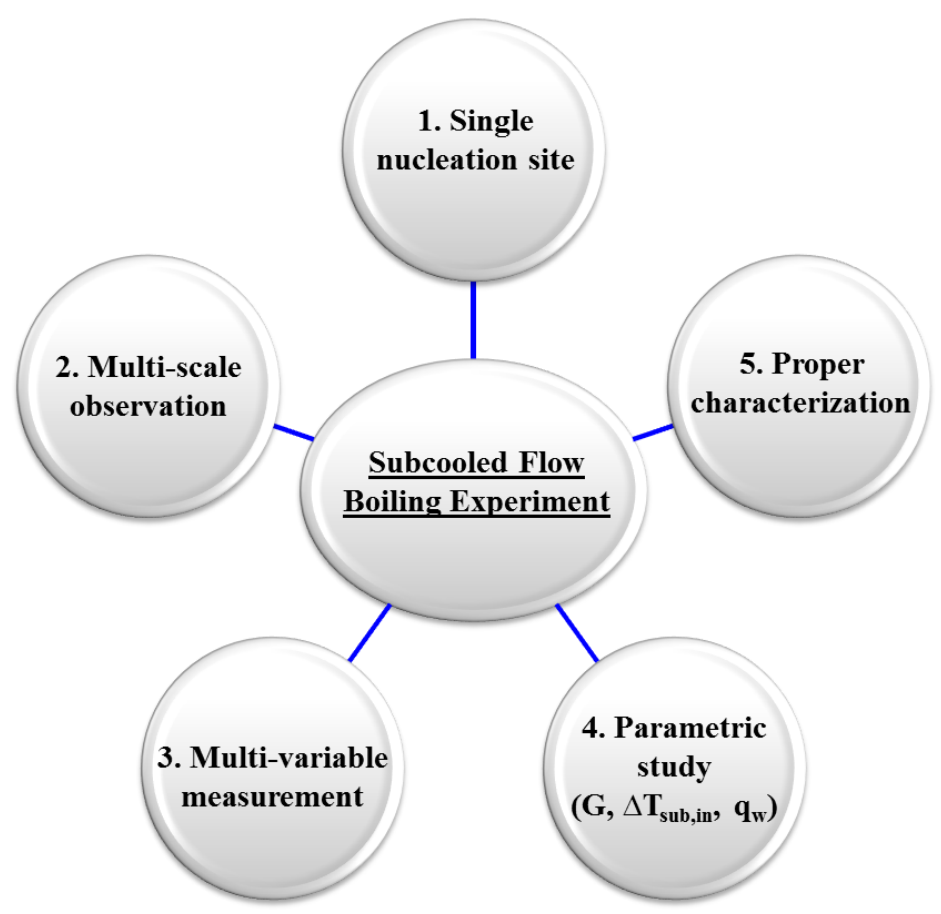

Figure 3. Strategy for enhancing the observation of subcooled flow boiling characteristics [1]

\section{TEST BOUNDARY CONDITIONS AND COLLECTED DATA}

The experimental data was taken at 16 different test conditions at atmospheric system pressure. The mass flux $(\mathrm{G})$, wall heat flux $\left(\mathrm{q}_{\mathrm{w}}\right)$, and inlet subcooling $\left(\mathrm{T}_{\text {sub,in }}\right)$ conditions for this experiment were selected to systematically observe the effect of changes in test boundary conditions on the bubble behaviors and associated wall heat transfer. In most test cases the bubbles departing from a single nucleation site tend to slide along the heated wall instead of lifting-off while travelling downward. Thus, the sliding bubble characteristics and their thermal effects under subcooled flow boiling conditions could be investigated from this experiment. In Table 1, 16 test conditions used in TAMU subcooled flow boiling experiment are summarized with bubble release frequency measured at each condition.

It is noted that more details on the data analysis including validation effort with the existing bubble departure frequency models (section 4) are described in Yoo et al. [9], and some results of those analyses are described in the following section. 
Table 1. Summary of test conditions in TAMU subcooled flow boiling experiment [9]

\begin{tabular}{cccccc}
\hline Exp. No. & $\begin{array}{c}G \\
\left(\mathrm{~kg} / \mathrm{m}^{2} \mathrm{~s}\right)\end{array}$ & $\begin{array}{c}q_{w} \\
\left(\mathrm{~kW} / \mathrm{m}^{2}\right)\end{array}$ & $\begin{array}{c}\Delta T_{\text {sub,in }} \\
(\mathrm{K})\end{array}$ & $J a^{a}$ & $\begin{array}{c}f_{b, 0}{ }^{b} \\
{[\mathrm{~Hz}]}\end{array}$ \\
\hline 1 & 140 & 9.7 & 13.5 & 34.1 & 159 \\
2 & 140 & 11.6 & 13.6 & 42.8 & 163 \\
3 & 140 & 8.1 & 13.5 & 24.1 & 152 \\
4 & 280 & 11.9 & 13.5 & 19.8 & 133 \\
5 & 420 & 12.2 & 13.5 & 6.3 & 239 \\
6 & 420 & 20.4 & 13.5 & 30.6 & 148 \\
7 & 420 & 23.7 & 13.5 & 39.5 & 282 \\
8 & 420 & 17.1 & 13.5 & 20.6 & 139 \\
9 & 560 & 24.0 & 13.6 & 24.2 & 207 \\
10 & 700 & 24.2 & 13.5 & 14.6 & 331 \\
11 & 700 & 30.9 & 13.5 & 27.1 & 343 \\
12 & 700 & 35.1 & 13.5 & 34.9 & 523 \\
13 & 700 & 26.4 & 13.6 & 18.4 & 295 \\
14 & 140 & 9.5 & 4.50 & 49.1 & 135 \\
15 & 420 & 20.1 & 4.50 & 45.8 & 380 \\
16 & 700 & 30.5 & 4.50 & 42.6 & 769 \\
\hline
\end{tabular}

${ }^{a}$ Jacob number at the elevation of nucleation site (estimated based on the average wall temperature measured at $L / L_{0} \approx 0.41$ )

${ }^{b}$ Bubble release frequency

\section{COMPARISON OF BUBBLE DEPARTURE FREQUENCY MODELS WITH THE TAMU EXPERIMENTAL DATA}

This section discusses the performance of bubble departure frequency models in literature by comparing them with the experimental results obtained from TAMU subcooled flow boiling experiment. It is noted that during TAMU subcooled flow boiling experiment vapor bubbles produced at the single nucleation site were generally in the interference bubble regime [10]. In other words, non-interactive and isolated bubbles were barely found at the nucleation site $\left(L / L_{0} \approx 0.41\right)$; therefore the departure frequency of isolated bubbles was hard to measure even with the high resolution camera HSC 1 (see Figure 1). Thus, instead of measuring the bubble departure frequency at the nucleation site, the frequency of isolated bubbles released from the nucleation site was investigated slightly downstream, i.e., $0.41<L / L_{0}<0.42$, and was defined as the bubble release frequency. The average value of bubble release frequency was obtained by considering typically more than 500 samples at each test condition based on the observation from HSC 1 (see Figure 1).

In Figure 4, the mean absolute deviation between the experimental measurements and the model predictions is shown with the five bubble departure frequency models available in literature. The models tested include: (i) Cole's model [11], (ii) Ivey's model [12], (iii) Zuber's model [13], (iv) Basu et al.'s model [5], and (v) Situ et al.'s model [14]. For low $\operatorname{Re}\left(\operatorname{Re} \approx 3125\right.$ or $G=140 \mathrm{~kg} / \mathrm{m}^{2} \mathrm{~s}$ ), Cole's (1960) model showed the best performance, showing less than $5 \%$ deviation from the data taken at both high and low subcooling conditions; but the prediction capability significantly deteriorated as Re increased. For higher $\operatorname{Re}(\operatorname{Re}>3125)$, Situ et al.'s (2008) model tended to predict the present data better than the other models. However, when comparing the prediction capability depending on Ja as shown on the right of Figure 4, Basu et al.'s (2005) model showed the best performance at Ja>34 while both Ivey's (1967) model and Situ et al.'s (2008) model predicted the present data comparably well at Ja $<34$. Based on these observations, the best performance region of the existing models depending on flow conditions can be defined as shown in Figure 5 ( $\varepsilon$ denotes the absolute mean deviation from the experimental data). 

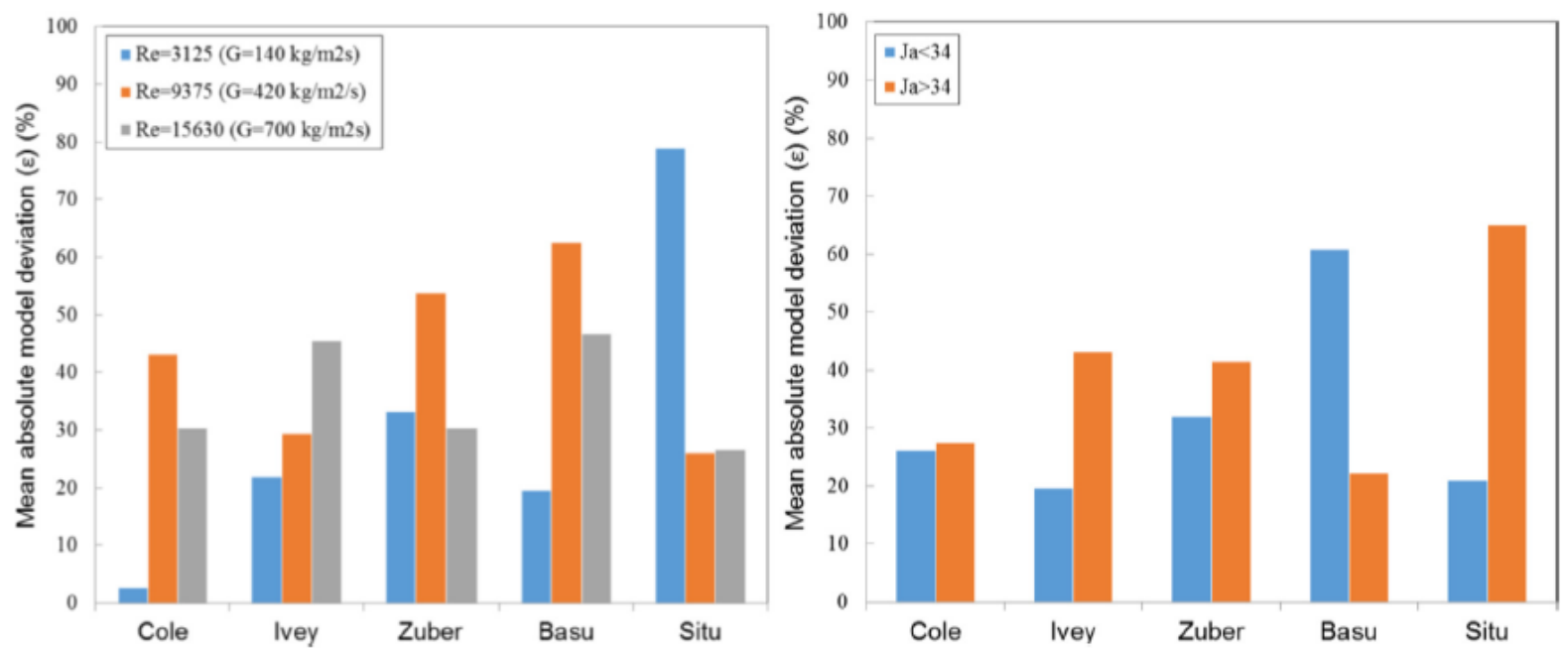

Figure 4. Prediction capability of bubble departure frequency models depending on Re (left) and Ja (right) [9]

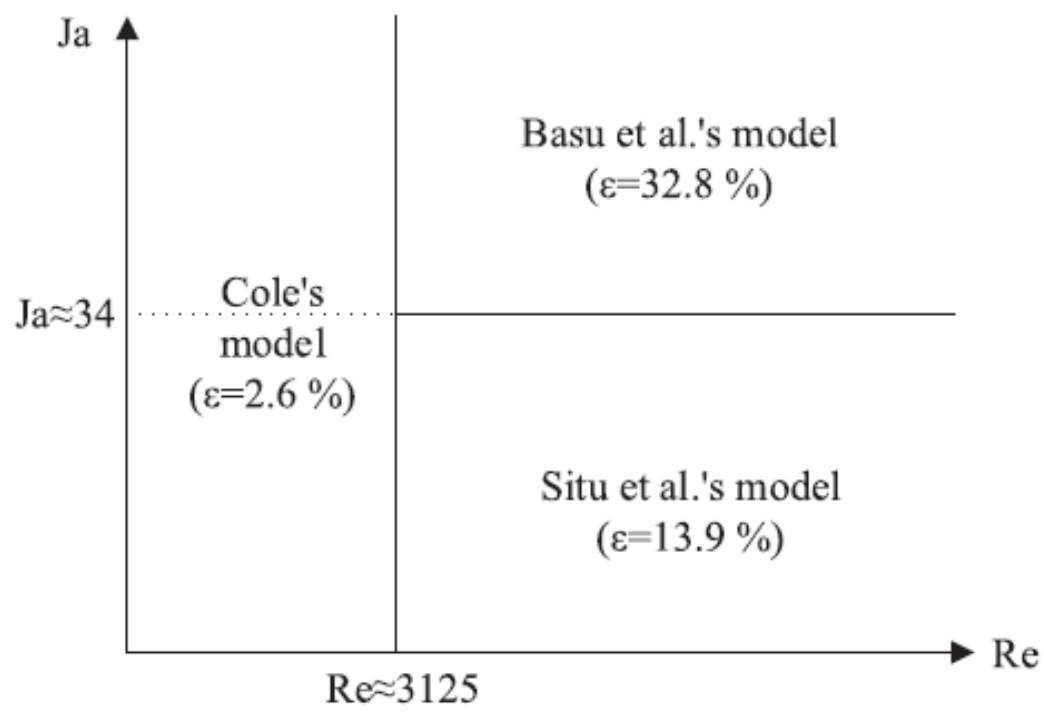

Figure 5. Best performance region of bubble departure frequency models depending on flow conditions [9]

Figure 6 also shows one experimental finding achieved from TAMU subcooled flow boiling experiment, showing how sensibly bubble release frequency was affected by the changes in test conditions like Ja depending on mass flux $(G)$. The Jacob numbers (Ja) shown in Figure 6 were estimated based on the average wall temperature measured at the elevation of nucleation site. The results shown in Figure 6 reveal that the bubble release frequency varied insignificantly at low $G$ (i.e., $G=140 \mathrm{~kg} / \mathrm{m}^{2} \mathrm{~s}$ or $\mathrm{Re} \approx 3125$ ) despite the significant changes in Ja, whereas the variation range significantly increased at higher $G$ (or Re). Recalling the discussion with Figures 4 and 5 above, the present study (Figures 4, 5, and 6) also reveals that no existing models available in literature can predict such observation of bubble departure frequency shown in Figure 6. 


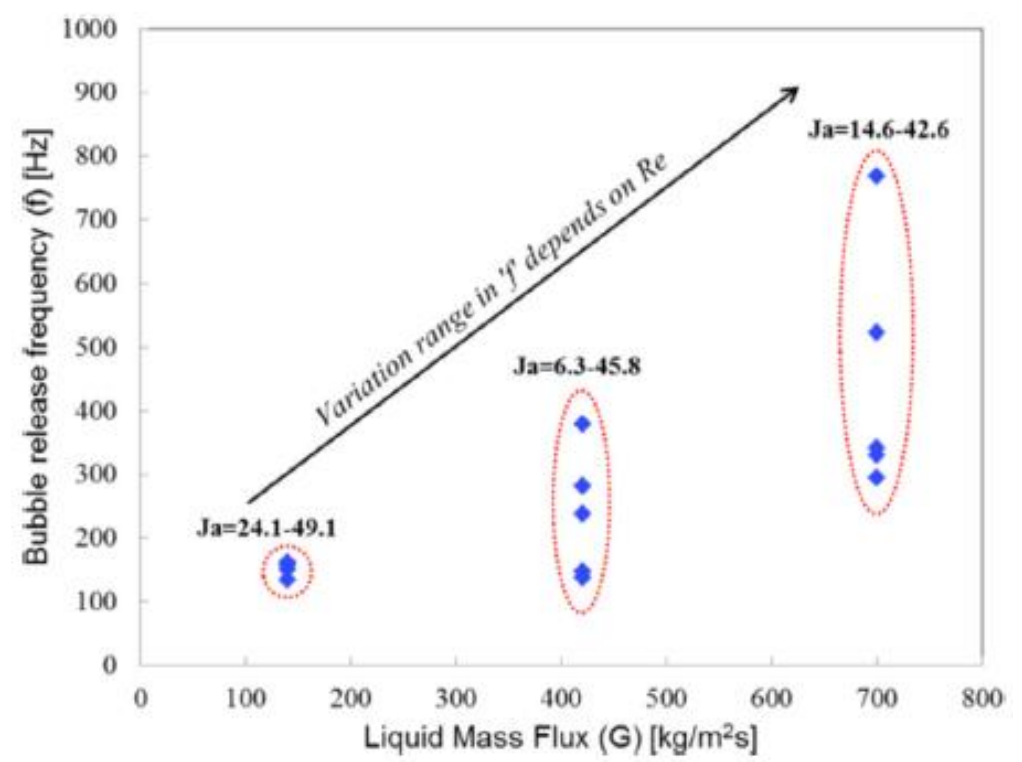

Figure 6. Variation of bubble release frequency by the changes in Ja at different mass fluxes (G) [9]

\section{IDENTIFICATION OF LIMITATION IN CFD BOILING MODEL APPROACH ADDRESSING SLIDING BUBBLE EFFECT}

\subsection{Experimental Observation}

The limitation of existing CFD boiling model approach associated with sliding bubble effect on wall heat transfer is discussed in this section. To identify such issue of existing models in CFD codes, TAMU subcooled flow boiling data, specifically the sliding bubbles' trajectory and its effect on wall heat transfer have been analyzed; and the results are discussed in relation to the existing CFD boiling model approach.

\subsubsection{Wall area influenced by sliding bubbles}

Figure 7 shows the general approach taken in CFD modelling $[5,6]$ to address the sliding bubbles' effect on wall heat transfer, assuming a straight and single path of sliding bubbles from a nucleation site. However, the experimental observation revealed that the bubbles emanating from a single nucleation site slid through various paths and the wall area swept by the sliding bubbles was often substantially larger than that covered by a single path. This implies that the wall area influenced by sliding bubbles at a given subcooled flow boiling condition is not just a function of bubble size (e.g., $A_{b}=K N \frac{\pi D_{b}^{2}}{4}$ in Kurul and Podowski's wall heat flux partitioning model [15]) but also closely related to the sliding bubbles' 
trajectory $\left(A_{b}\right.$ is wall area of bubble influence; $K$ is bubble influence factor; $N$ is active nucleation site density; $D_{b}$ is bubble diameter). Thus, to clarify the unknown physics concerning the influential area of sliding bubbles in subcooled boiling flow, the characteristic of sliding bubbles' trajectory and its thermal effect on wall heat transfer must be understood better.

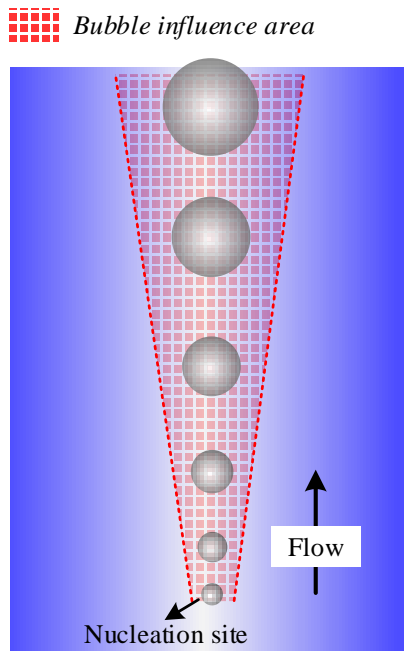

CFD models to address sliding bubble effect

Figure 7. Sliding bubble trajectory assumed in CFD models

In this regard, efforts were made to quantify the characteristic of sliding bubbles' trajectory, for which sliding bubbles' spreading factor $S$ and bubble influence factor $K$ are defined as follows:

$$
S=\frac{\text { Area swept by sliding bubbles }}{D_{\text {avg }} \times l_{s}}
$$

(where $S$ is the sliding bubble spreading factor; $D_{\text {avg }}$ is the average sliding bubble diameter within the sliding distance; $l_{s}$ is the sliding distance)

$$
K=\frac{A_{i}}{D_{\text {avg }} \times l_{s}}
$$

(where $K$ is the bubble influence factor; $A_{i}$ is the wall area influenced by sliding bubbles).

The bubble spreading factor $S$ represents how widely the sliding bubbles emanating from the single nucleation site spread in lateral direction relative to the bubble size while travelling. It is noted that the numerator in Eq. (1) 'area swept by sliding bubbles' was obtained by analyzing the bubbles' trajectories captured from the top of sliding bubbles with the heater wall defined as the bottom (HSC 3, see Figure 1); $D_{\text {avg }}$ in Eqs. (1) and (2) was obtained using the observation from both HSC 1 (near nucleation site) and HSC 3 (downstream). In particular, to characterize the 'area swept by sliding bubbles' during the measurement period ( $80 \mathrm{sec}$ ) 40,000 images, specifically binary images achieved through image processing [1] were analyzed at each test condition. For the bubble influence factor $K$ which determines the effective area influenced thermally by sliding bubbles, $A_{i}$ in Eq. (2) was evaluated based on the thermal images (1,700 images were analyzed at each test) obtained from IR camera (see Figure 1). In 
Figure 7, the evaluation of $S$ and $K$ using both sliding bubble images and IR thermal images taken during the TAMU subcooled flow boiling experiment is illustrated.

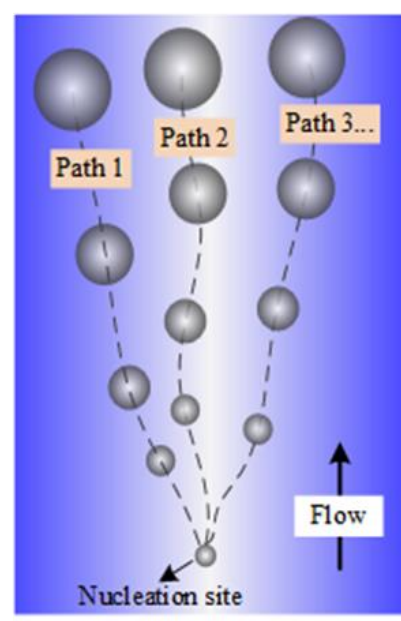

Sliding bubbles released from a single nucleation site
Bubble size \& Trajectory

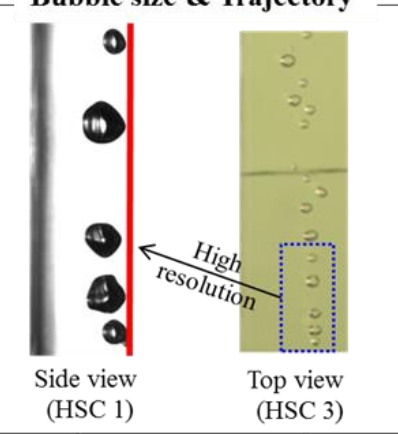

" $S$ " and $K$ ?
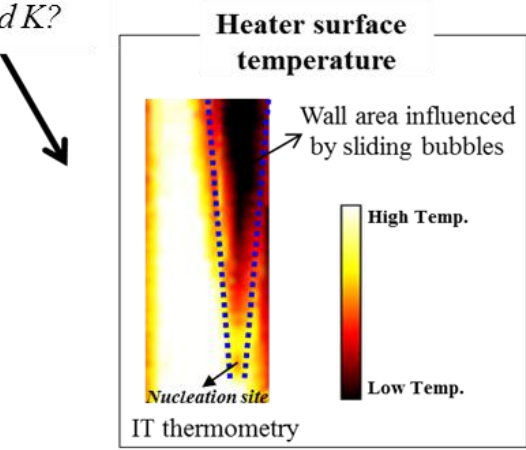

Figure 8. Measurement of sliding bubble spreading area $(S)$ and bubble influence area $(K)$

The experimental results shown in Figure 9 reveal that the bubble influence factor $K$ is closely related to the sliding bubble size $\left(D_{\text {avg }}\right)$. Specifically, $K$ evaluated within the region $0.41 \leq \mathrm{L} / \mathrm{L}_{0} \leq 0.43$ decreased as $D_{\text {avg }}$ became larger, and the similar relation was found between $S$ and $D_{\text {avg. }}$. In addition, when comparing the present results for $K$ with the values reported in literature for departing or lifting-off bubbles (i.e., $K=4$ for C.-Y. Han, P. Griffith [16], $K=1.8$ for R. Judd and K. Hwang [17]) which have still been widely adopted $[6,15,18-20]$, Figure 9 shows that $K$ values measured in this work were often observed significantly larger especially for the smaller sliding bubbles. This is due to the fact that the wall area swept by smaller bubbles (i.e., sliding paths or trajectories) was substantially larger than the sliding bubble size $\left(D_{\text {avg }}\right)$ (see Eq. (1)). In particular, this result obviously pinpoints the deficiency of existing CFD approach addressing the sliding bubbles' thermal effect through a constant $K$ which cannot account for the effect of bubbles' sliding characteristic. 


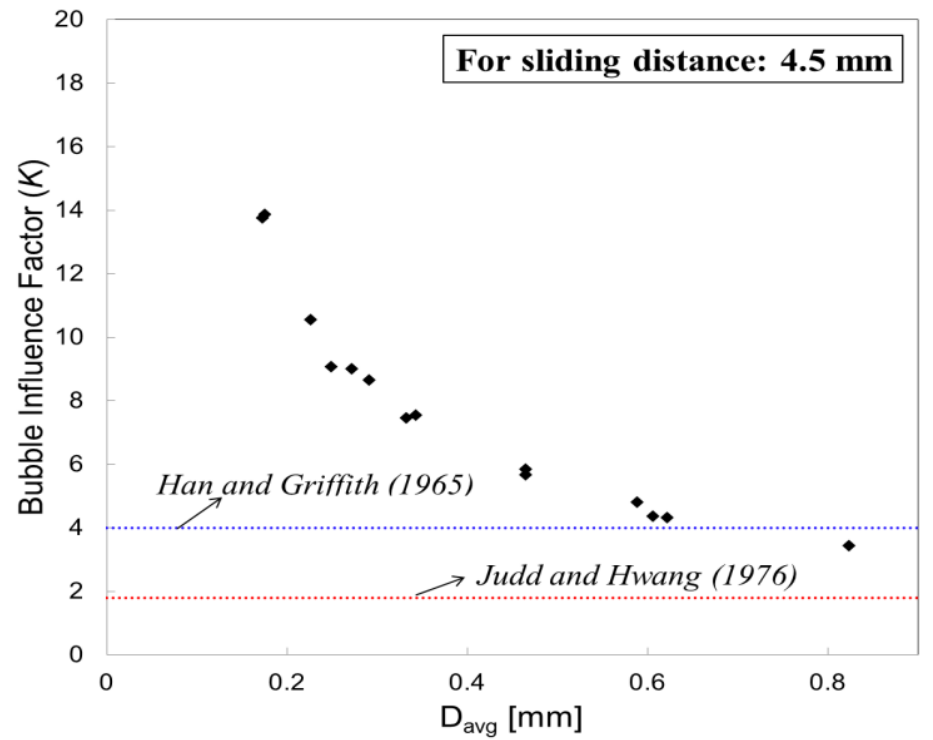

Figure 9. Bubble influence factor $(\mathrm{K})$ depending on the size of sliding bubble for a given sliding distance

\subsubsection{Temporal fraction of sliding bubble residence}

Another aspect of bubbles' sliding effect that has been investigated in this work is the temporal fraction of bubbles' residence along the heated wall during the measurement period (hereafter, $F_{R}$ ). This is important in the sense that $F_{R}$ provides detailed information on both the area swept by sliding bubbles during measurement period and the 'effective' sliding bubble frequency passing through that area, which will directly affect the wall heat transfer mode like quenching or micro-convection influenced by sliding bubbles [6]. The two types of $F_{R}$ can be defined as follows:

$$
\overline{F_{R}}(y)=\int_{0}^{S_{0}} \overline{F_{R}}(y, z) d z / \int_{0}^{S_{0}} d z
$$

(where $\overline{F_{R}}(y, z)$ is the temporal fraction of bubble residence during the measurement period at a location $(\mathrm{y}, \mathrm{z})$ on the heater wall; $\overline{F_{R}}(y)$ is the average temporal fraction of bubble residence at axial location $y ; S_{0}$ is the heater width swept by sliding bubbles at a given axial location)

$$
\overline{F_{R}}=\int_{0}^{l_{s}} \int_{0}^{S_{0}} \overline{F_{R}}(y, z) d y d z / \int_{0}^{l_{s}} \int_{0}^{S_{0}} d y d z
$$

(where $\overline{F_{R}}$ is the area-averaged time fraction of bubble residence within sliding distance $l_{s}$ ).

It is noted that the recording speed of high-speed camera (i.e., HSC 3) should be low enough to take independent samples of sliding bubbles at a given location per each frame, which is essential to ensure the high statistical significance of $F_{R}$ evaluated using Eqs. (3) and (4). 
Figure 10 shows how the sliding bubble path and $\overline{F_{R}}(y, z)$ typically varied along the flow path after the bubbles departed from the single nucleation site (axial location of nucleation site: $\mathrm{L} / \mathrm{L}_{0} \approx 0.41$ ). The bubbles slid through narrow path with high $\overline{F_{R}}(y, z)$ near the nucleation site, whereas the sliding bubbles swept wider area and $\overline{F_{R}}(y, z)$ decreased as the bubbles travelled downstream. This means that at the downstream region less number of sliding bubbles passed "per unit area" of bubble influence although the influential area of sliding bubbles became larger. Thus, the sliding bubbles' effect "per unit area" can be limited. This sliding bubbles' characteristic caused larger wall temperature gradient across the heater width near the nucleation site while such gradient significantly smeared out downstream [7]. That is, the sliding bubbles' impact on wall heat transfer was noticeable near the nucleation site but the influence was restricted to relatively narrow region; and this observation became reversed downstream. Also, we can expect from this observation that the wall heat transfer mode like quenching or micro-convection heat transfer induced by sliding bubbles [6] will depend on the distance from nucleation site.

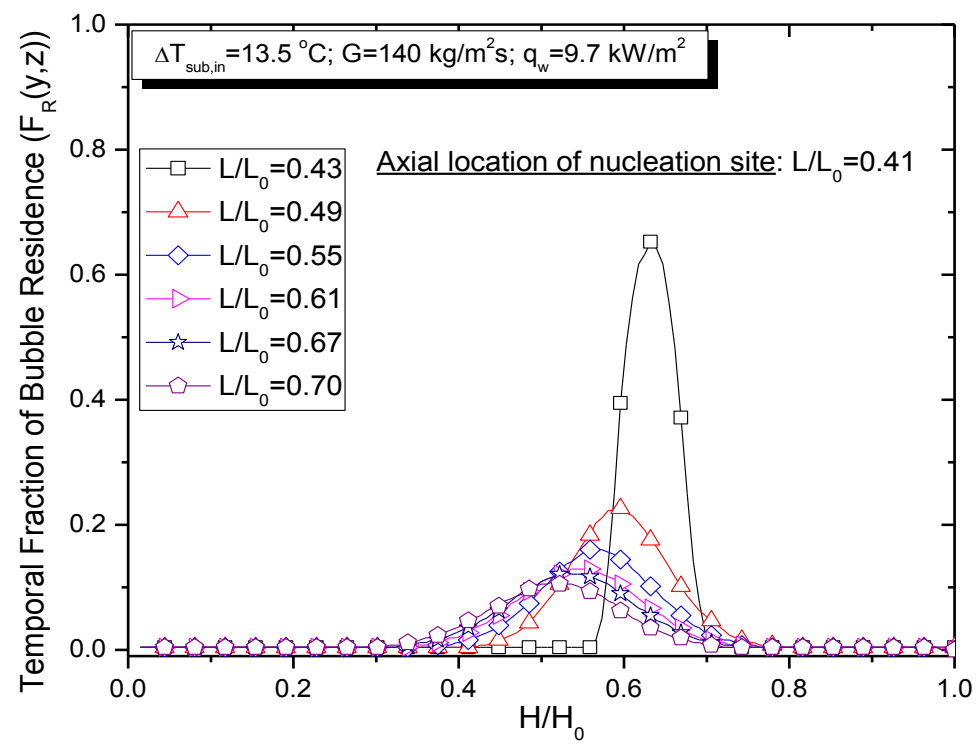

Figure 10. A typical development of $\overline{F_{R}}(y, z)$ along the flow path $\left(\mathrm{H}_{0}\right.$ is heater width $(=7.5 \mathrm{~mm})$ and $\mathrm{H}$ is horizontal position within $\mathrm{H}_{0}$ )

Figure 11 shows the relation between $\overline{F_{R}}$ (see Eq. (4)) and bubble spreading factor $S$ observed from the experiment. We can see here that $\overline{F_{R}}$ decreased as $S$ increased and the relation was consistent regardless of the sliding distance $l_{s}$. Considering that $S$ has been observed to have proportional relation with $K$, the similar relation is also expected between $\overline{F_{R}}$ and $K$. Another finding from Figure 11 is that $S$ was estimated higher as the sliding distance $\left(l_{s}^{*}\right)$ increased which is due to the fact that bubbles slid through wider path as they travelled downstream as discussed before. 


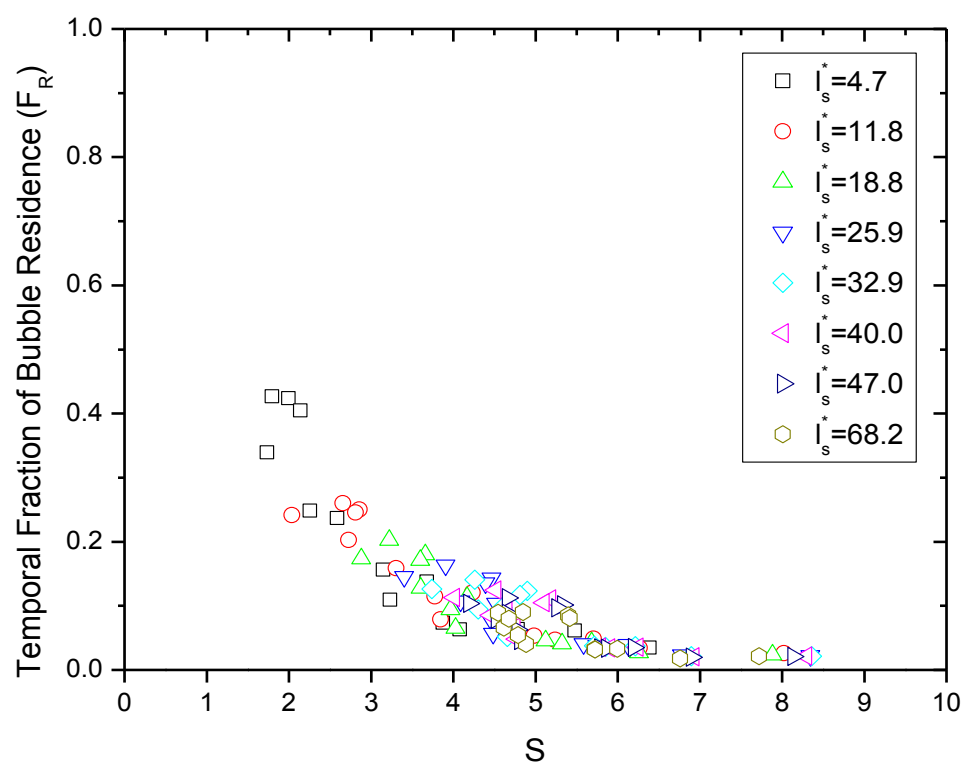

Figure 11. Observed relation between $\overline{F_{R}}$ and $\mathrm{S}\left(l_{s}^{*}=l_{\S} / \sqrt{\sigma /(g \Delta \rho)}\right)$

In Figure 12, the increase in wall heat transfer through the bubbles' sliding distance $l_{s}{ }^{*}=11.8$ depending on $\overline{F_{R}}$ is shown, the results of which were taken at 14 different test conditions. The results show that higher $\overline{F_{R}}$ tended to cause higher increase in wall heat transfer (i.e., $\mathrm{H}_{\text {downstream }} / \mathrm{H}_{\text {upstream }}$ ). This implies that $\overline{F_{R}}$ significantly affected the degree of wall heat transfer enhancement induced by sliding bubbles, and $\overline{F_{R}}$ is strongly dependent on the characteristic of sliding bubbles' trajectory like $S$ (see Figure 11 ). As discussed before, it is noted that $\overline{F_{R}}$ is physically related to the quenching or micro-convection heat transfer caused by sliding bubbles within the wall area of bubble influence.

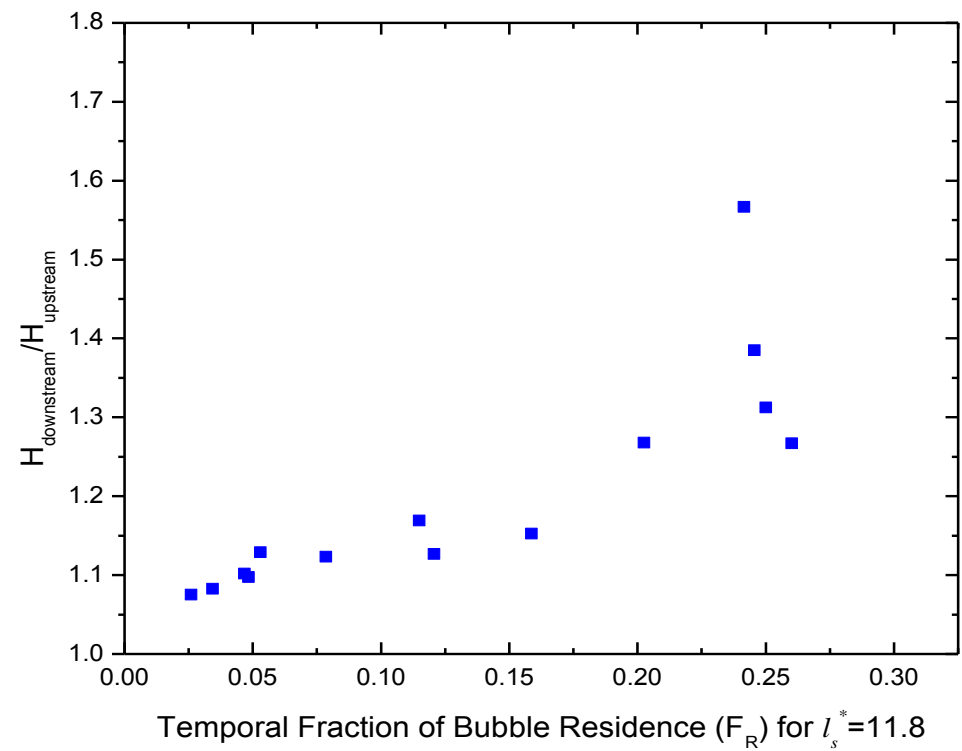

Figure 12. Degree of wall heat transfer enhancement $\left(\mathrm{H}_{\text {downstream }} / \mathrm{H}_{\text {upstream }}\right)$ through the sliding distance $l_{s}^{*}=11.8$ depending on $F_{R}$ 


\subsection{New/lmproved Modeling Need and Ongoing Work in INL}

The experimental observation described in section 5.1 clearly identifies the knowledge gap between the existing CFD boiling models and the actual physics observed, specifically the modeling approach dealing with sliding bubble effect on wall heat transfer. Also, it is obvious, in order to fill the gap, new physical insight achieved from TAMU subcooled flow boiling experiment should be accounted for within the present CFD boiling model framework. In this regard, a new model predicting the sliding bubble characteristics such as bubble influence factor $(K)$ and bubble spreading factor $(S)$ will be of substantial help to improve the existing modeling approach for the sliding bubbles. Also, the recent data analysis reveals that $K$ and $S$ are a function of both sliding bubble diameter $\left(D_{\text {slide }}\right)$ and sliding distance $\left(l_{\text {slide }}\right)$ as shown in Figure 13. Also, based on these findings, effort is currently being made in INL to develop a new model/correlation that can specifically apply to the prediction of $K$ and $S$ for the sliding bubbles.

The new model/correlation will be provided in this section (updated version of this report) as soon as the final model/correlation form becomes available. 

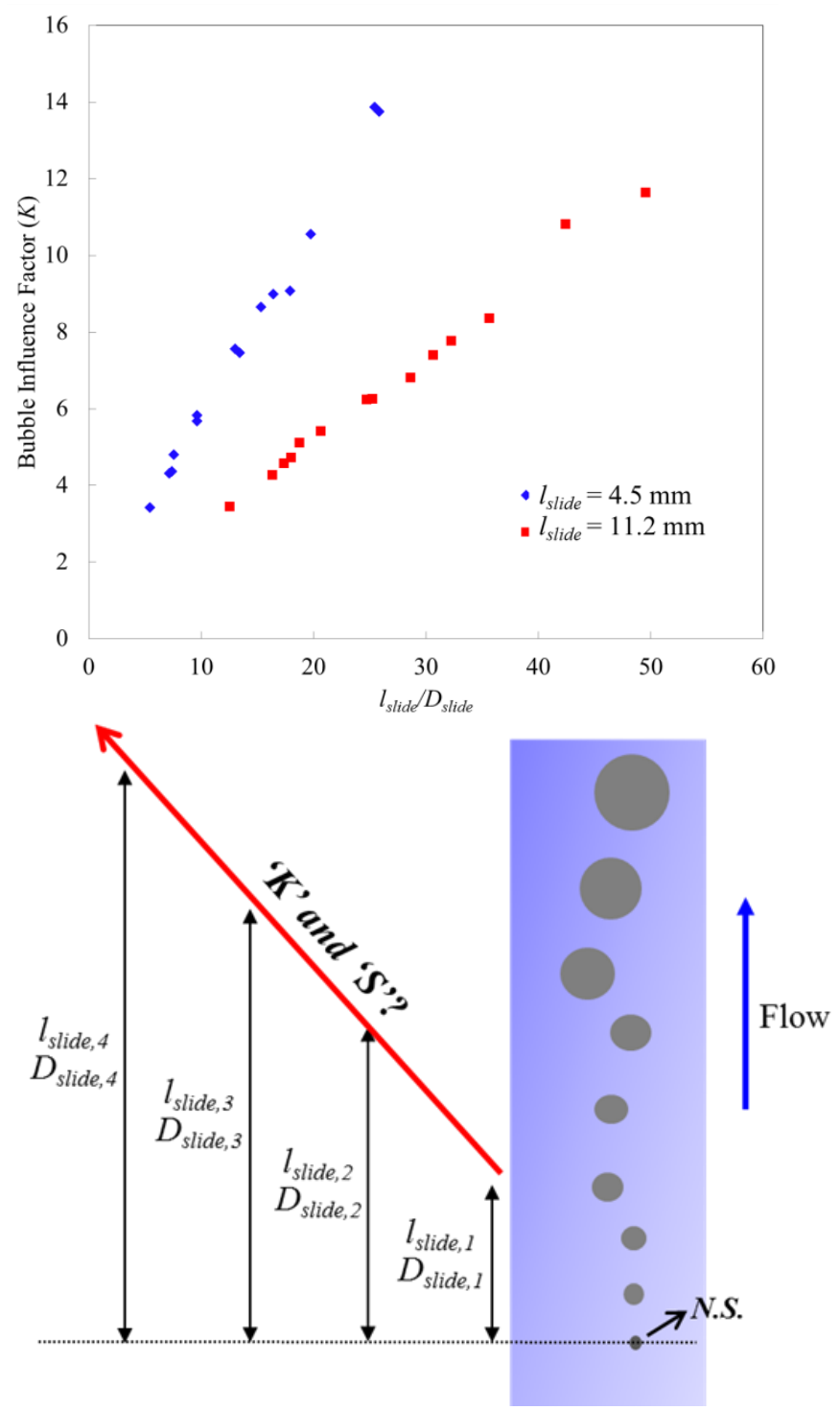

Figure 13. New experimental finding (top) and modeling strategy (bottom) for bubble influence factor $(K)$ and bubble spreading factor $(S)$

\section{SUMMARY AND CONCLUSIONS}

The experimental data taken from TAMU subcooled flow boiling facility with a single nucleation site approach have been collected and analyzed, the results of which are discussed in this report. At first, the performance of bubble departure frequency models available in literature is discussed by comparing the model predictions with the experimental data. This work allows us to identify the predictive capability of existing bubble departure frequency models depending on flow conditions, from which the best performance condition of each model can also be determined.

Another critical achievement through this work is that the limitation of existing CFD boiling models dealing with sliding bubble effect is clearly identified. In particular, the experimental observation shows 
that the wall area influenced by sliding bubbles is not just a function of bubble size, but also depends strongly on sliding bubble trajectory and sliding distance. As a result, the values of bubble influence factor $K$ are found to be substantially higher than those reported in literature especially for the smaller size of sliding bubbles. This is because the smaller bubbles spread more in lateral direction compared to their size while sliding downward. In addition, the sliding bubble trajectory is found to significantly influence the temporal fraction of bubble residence while sliding, which subsequently affects the degree of wall heat transfer enhancement by the sliding bubbles.

Importantly, the observations from TAMU subcooled flow boiling experiment help specify the knowledge gap between the existing CFD boiling models dealing with sliding bubbles and the actual physics. Also, it is concluded that the new physical insight achieved from the TAMU experiment should be accounted for to improve the existing CFD boiling model. In this context, a model development effort is currently being made in INL, especially by focusing on the models to predict the sliding bubble characteristics such as bubble spreading factor $(S)$ and bubble influence factor $(K)$. 


\section{References}

1. Yoo, J., C.E. Estrada-Perez, and Y.A. Hassan, Experimental study on bubble dynamics and wall heat transfer arising from a single nucleation site at subcooled flow boiling conditions-Part 1: Experimental methods and data quality verification. International Journal of Multiphase Flow, 2016. 84: p. 315-324.

2. Cornwell, K., The influence of bubbly flow on boiling from a tube in a bundle. International Journal of Heat and Mass Transfer, 1990. 33(12): p. 2579-2584.

3. Houston, S. and K. Cornwell, Heat transfer to sliding bubbles on a tube under evaporating and non-evaporating conditions. International journal of heat and mass transfer, 1996. 39(1): p. 211214.

4. Thorncroft, G. and J. Klausner, The influence of vapor bubble sliding on forced convection boiling heat transfer. Journal of Heat Transfer, 1999. 121(1): p. 73-79.

5. Basu, N., G.R. Warrier, and V.K. Dhir, Wall heat flux partitioning during subcooled flow boiling: Part 1-model development. Journal of heat Transfer, 2005. 127(2): p. 131-140.

6. Yeoh, G., et al., Fundamental consideration of wall heat partition of vertical subcooled boiling flows. International Journal of Heat and Mass Transfer, 2008. 51(15): p. 3840-3853.

7. Yoo, J., C.E. Estrada-Perez, and Y.A. Hassan, An accurate wall temperature measurement using infrared thermometry with enhanced two-phase flow visualization in a convective boiling system. International Journal of Thermal Sciences, 2015. 90: p. 248-266.

8. Yoo, J., C.E. Estrada-Perez, and Y.A. Hassan, A proper observation and characterization of wall nucleation phenomena in a forced convective boiling system. International Journal of Heat and Mass Transfer, 2014. 76: p. 568-584.

9. Yoo, J., C.E. Estrada-Perez, and Y.A. Hassan, Experimental study on bubble dynamics and wall heat transfer arising from a single nucleation site at subcooled flow boiling conditions-Part 2: Data analysis on sliding bubble characteristics and associated wall heat transfer. International Journal of Multiphase Flow, 2016. 84: p. 292-314.

10. Zuber, N., Nucleate boiling. The region of isolated bubbles and the similarity with natural convection. International Journal of Heat and Mass Transfer, 1963. 6(1): p. 53-78.

11. Cole, R., A photographic study of pool boiling in the region of the critical heat flux. AIChE Journal, 1960. 6(4): p. 533-538.

12. Ivey, H., Relationships between bubble frequency, departure diameter and rise velocity in nucleate boiling. International Journal of Heat and Mass Transfer, 1967. 10(8): p. 1023-1040.

13. Zuber, N., Hydrodynamic aspects of boiling heat transfer (thesis). 1959, California. Univ., Los Angeles; and Ramo-Wooldridge Corp., Los Angeles.

14. Situ, R., et al., Bubble departure frequency in forced convective subcooled boiling flow. International Journal of Heat and Mass Transfer, 2008. 51(25): p. 6268-6282.

15. Kurul, N. and M.Z. Podowski. Multidimensional effects in forced convection subcooled boiling. in Proceedings of the 9th International Heat Transfer Conference. 1990. Jerusalem, Israel: Hemisphere Publishing Corporation.

16. Han, C.-Y., P. Griffith, and C. Yeh. The mechanism of heat transfer in nucleate pool boiling II. in International Journal of Heat and Mass Transfer. 1965. Citeseer.

17. Judd, R. and K. Hwang, A comprehensive model for nucleate pool boiling heat transfer including microlayer evaporation. Journal of Heat Transfer, 1976. 98(4): p. 623-629.

18. Krepper, E. and R. Rzehak, CFD for subcooled flow boiling: Simulation of DEBORA experiments. Nuclear Engineering and Design, 2011. 241(9): p. 3851-3866.

19. Bae, B.-U., et al., Analysis of subcooled boiling flow with one-group interfacial area transport equation and bubble lift-off model. Nuclear Engineering and Design, 2010. 240(9): p. 2281-2294. 
20. Tu, J. and G. Yeoh, On numerical modelling of low-pressure subcooled boiling flows. International Journal of Heat and Mass Transfer, 2002. 45(6): p. 1197-1209. 


\section{Appendix A. Experimental data}

In this section, experimental data used to derive the model/correlation predicting the bubble spreading factor $(S)$ and bubble influence factor $(K)$ (section 5.2) will be attached as soon as they become available. 